\title{
Conservative Treatment in Diverticulitis Patients with Pericolic Extraluminal Air and the Role of Antibiotic Treatment
}

\author{
H. E. Bolkenstein ${ }^{1,2}$ (D) S. T. van Dijk ${ }^{3}$ - E. C. J. Consten ${ }^{2}$ - B. G. F. Heggelman ${ }^{4}$ - C. M. A. Hoeks ${ }^{4}$ - I. A. M. J. Broeders ${ }^{5}$. \\ M. A. Boermeester ${ }^{3} \cdot$ W. A. Draaisma ${ }^{6}$
}

Received: 30 September 2018 / Accepted: 2 February 2019 / Published online: 11 March 2019

(C) 2019 The Author(s)

\begin{abstract}
Background Recently published studies advocate a conservative approach with observation and antibiotic treatment in diverticulitis patients with pericolic air on computed tomography (CT). The primary aim of this study was to assess the clinical course of initially conservatively treated diverticulitis patients with isolated pericolic air and to identify risk factors for conservative treatment failure. The secondary aim was to assess the outcome of non-antibiotic treatment.

Methods Patient data from a retrospective cohort study on risk factors for complicated diverticulitis were combined with data from the DIABOLO trial, a randomised controlled trial comparing non-antibiotic with antibiotic treatment in patients with uncomplicated diverticulitis. The present study identified all patients with Hinchey 1A diverticulitis with isolated pericolic air on CT. Pericolic air was defined as air located $<5 \mathrm{~cm}$ from the affected segment of colon. The primary outcome was failure of conservative management which was defined as need for percutaneous abscess drainage or emergency surgery within 30 days after presentation. A multivariable logistic regression of clinical, radiological and laboratorial parameters with respect to treatment failure was performed.

Results A total of 109 patients were included in the study. Fifty-two (48\%) patients were treated with antibiotics. Nine (8\%) patients failed conservative management, seven (13\%) in the antibiotic treatment group and two (4\%) in the non-antibiotic group $(p=0.083)$. Only (increased) CRP level at presentation was an independent predictor for treatment failure.

Conclusions Conservative treatment in diverticulitis patients with isolated pericolic air is a suitable treatment strategy. Moreover, non-antibiotic treatment might be reasonable in selected patients.
\end{abstract}

Keywords Diverticulitis $\cdot$ Pericolic air $\cdot$ Conservative treatment $\cdot$ Antibiotic treatment

H. E. Bolkenstein

he.bolkenstein@meandermc.nl

S. T. van Dijk

stefanvandijk@amc.uva.nl

E. C. J. Consten

ecj.consten@meandermc.nl

B. G. F. Heggelman

bgf.heggelman@meandermc.nl

C. M. A. Hoeks

cma.hoeks@meandermc.nl

I. A. M. J. Broeders

iamj.broeders@meandermc.nl

M. A. Boermeester

m.a.boermeester@amc.uva.nl
W. A. Draaisma

w.draaisma@jbz.nl

1 University of Twente, 5, Drienerlolaan, 7522, NB

Enschede, The Netherlands

2 Department of Surgery, Meander Medisch Centrum, 3800, BM Amersfoort, The Netherlands

3 Department of Surgery, Academic Medical Centre, Amsterdam, The Netherlands

4 Department of Radiology, Meander Medical Centre, Amersfoort, The Netherlands

5 Department of Surgery, Meander Medical Centre, Amersfoort, The Netherlands

6 Department of Surgery, Jeroen Bosch Hospital, 's-Hertogenbosch, The Netherlands 


\section{Introduction}

Colonic diverticulosis is primarily seen in the Western population with prevalence increasing with age. At 40 years of age, approximately $10 \%$ of the Western population has diverticulosis, while this number increases up to $70 \%$ in octogenarians. About $4-7 \%$ of patients with diverticulosis will develop diverticulitis. ${ }^{1,2}$ Twenty-five per cent of diverticulitis patients develops complications such as abscess or colonic perforation. ${ }^{3}$ Uncomplicated diverticulitis is usually treated conservatively, whereas complicated diverticulitis is treated with percutaneous abscess drainage or operative intervention (emergency resection or laparoscopic lavage). ${ }^{4}$ Most classification systems that categorise diverticulitis are based on computed tomography (CT) findings, such as fluid collections, extraluminal contrast leakage or free air. ${ }^{5-8}$ The clinical relevance of free air on CT remains unclear. Large amounts of distant free air on CT is usually considered a sign of diffuse peritonitis and warrants caution as operative intervention is often needed, whereas patients who present with isolated pericolic air may be treated conservatively. ${ }^{9}$ Current guidelines on treatment of diverticulitis do not describe uncomplicated diverticulitis patients with isolated pericolic air nor do they advise on the optimal treatment strategy. ${ }^{10}$ Recently published studies advocate a conservative approach with observation and antibiotic treatment. These studies are however hampered by small or heterogeneous study populations (including patients with pericolic and distant free air) or inadequate outcome parameters (not including percutaneous drainage as a treatment failure), hindering direct translation to clinical practice. ${ }^{11-15}$ The primary aim of the present study was therefore to assess the course of uncomplicated diverticulitis patients with isolated pericolic air seen on $\mathrm{CT}$ imaging and to identify risk factors for failure of conservative treatment. The second aim was to assess the outcome of non-antibiotic treatment in this patient group.

\section{Materials and Methods}

\section{Study Design}

The present study was a joint venture between the DIABOLO trial $^{16}$, a multicenter randomised controlled trial comparing antibiotic with non-antibiotic treatment in 528 patients with uncomplicated acute diverticulitis ${ }^{17-19}$, and a retrospective cohort study in 943 patients studying risk factors for complicated diverticulitis performed in the Meander Medical Centre. The DIABOLO $^{16}$ trial prospectively included all patients with Hinchey 1A and 1B diverticulitis between June 2010 and October 2012 whereas for the retrospective cohort, a diagnostic specific code was used to identify all patients presenting with an episode of diverticulitis in the emergency department between January 2005 and January 2017. The study was approved by the local Institutional Review Board of the Meander Medical Centre.

\section{Study Population}

This study included all patients with an uncomplicated diverticulitis (only modified Hinchey $1 \mathrm{~A})^{17-19}$ with pericolic air on CT. Only patients presenting without signs of sepsis and no clinical or radiological evidence of an abscess or diffuse peritonitis at presentation were included. ${ }^{20}$ Patients who received emergency surgery or abscess drainage within $24 \mathrm{~h}$ after presentation were also excluded. Imaging was performed using spiral CT scanners (Siemens SOMATOM: Sensation 16, Definition AS, Definition Flash) with the patient in supine position. Axial slices were spaced at $3 \mathrm{~mm}(\mathrm{~mm})$ (Definition AS / Flash) or $5 \mathrm{~mm}$ (Sensation 16) intervals and contained $512 \times 512$ pixels. Intravenous contrast (Xenetix 300/350, Guerbet, The Netherlands) was administered (unless the patient had a contraindication for intravenous contrast). All CT-reports were checked for mentioning of the following signs; "pericolic air bubbles or pockets", "pericolic free air or gas", "intraperitoneal free air or gas", "extraluminal air" or "covered perforation". Subsequently, these CTs were re-analysed by two independent radiologists for the presence and classification of extraluminal air on CT. Both radiologists were blinded for patient characteristics, initial CT report from the participating hospital, CT report from the other expert reader and patient outcome. In line with previous published literature ${ }^{11-15}$, pericolic air was defined as air located less than $5 \mathrm{~cm}$ from the affected segment of colon, regardless of whether the air was intra- or retroperitoneal. Only patients in whom both radiologists reported extraluminal air $<5 \mathrm{~cm}$ from the affected segment were included. Patients without extraluminal air or extraluminal air $>5 \mathrm{~cm}$ from the affected segment were excluded from analysis. The volume of extraluminal air was estimated by measuring the air pocket's largest diameter in two directions in the axial plane and in the coronal plane. The presence of free fluid was scored, as well as the location of free fluid (pericolic, Douglas' pouch or diffuse).

\section{Data Collection and Outcomes}

Patient characteristics, clinical signs and symptoms, American Society of Anesthesiologists (ASA) Physical Status classification scores, laboratory parameters (C-reactive protein (CRP) and leucocyte level at presentation), CT-findings and initial treatment strategy (e.g. antibiotic treatment, watchful waiting), were collected from the hospital records. The primary outcome was failure of conservative management which was defined as need for emergency surgery or percutaneous abscess 
drainage within 30 days after presentation. The occurrence of failure of conservative treatment was determined retrospectively in both study cohorts. Secondary outcome measures were length of hospital stay, complications (colonic obstruction, abscess, perforation) and mortality. Moreover, the primary outcome per initial treatment strategy (antibiotic or nonantibiotic treatment) was assessed. For the patients from the retrospective cohort, patients were assigned to the antibiotic treatment group if antibiotic treatment had been started within $24 \mathrm{~h}$ after presentation. Antibiotic treatment was not started according to a predefined protocol but at the discretion of the attending physician.

\section{Statistical Analysis}

Descriptive statistics were provided of all variables. Continuous variables are presented as means with standard deviation (SD) or medians with inter quartile range (IQR) according to their distribution. For categorical variables, counts and percentages are presented. Categorical variables were compared using the chi-square test or Fisher's exact test, as appropriate, and continuous variables were compared using the independent $t$ test or the Mann-Whitney $U$ test, as appropriate. Multivariable logistic regression was performed to identify risk factors for failure of conservative treatment. Variables that were univariably associated $(p<0.20)$ with failure of conservative treatment were entered into the multivariable model. Odds ratios are presented with $95 \%$ confidence intervals. Two sided $P<0.05$ was considered statistically significant. All analyses were performed using the statistical software package SPSS 24.0 (IBM Corporation, New York, USA).

\section{Results}

\section{Patient Characteristics}

Figure 1 depicts the selection of patients presenting with acute Hinchey 1A diverticulitis with pericolic air on CT form the two cohorts. In total, 1471 diverticulitis patients were identified. Of these, 214 patients were excluded because of clinical or radiological signs of peritonitis or abscess (Hinchey classification > 1A). In 146 (12\%) of the 1257 Hinchey $1 \mathrm{~A}$ patients, extraluminal air was reported in the initial CT reports. These patients were all initially treated conservatively. Thirty-five patients were excluded because at re-evaluation, no extraluminal air was observed $(n=25)$ or the extraluminal air was located more than $5 \mathrm{~cm}$ of the affected segment $(n=$ 10). After exclusion of two duplicate patients, a total of 109 patients were included in the present study; 39 patients from the DIABOLO ${ }^{14}$ trial and 70 patients from the retrospective single-centre cohort. Baseline characteristics are shown in
Table 1. The mean age was 53 years (SD 11) and $33 \%$ of the patients were female. Median amount of extraluminal air was $1.5 \mathrm{cc}$ (IQR 1.0-2.5). Radiologists reported free fluid in $12(11 \%)$ patients which was most frequently seen in Douglas' pouch $(n=11)$. Fifty-two $(48 \%)$ patients received antibiotic treatment within $24 \mathrm{~h}$ after presentation. Baseline characteristics were mostly comparable between the antibiotic and nonantibiotic group. CRP level seemed to be slightly higher in the antibiotic group (median 142 versus $115 \mathrm{mg} / \mathrm{L}$ ). The volume of pericolic air was significantly higher in the antibiotic group (median $2.0 \mathrm{cc}$ versus $1.5 \mathrm{cc}$ ) compared to the non-antibiotic group.

\section{Primary Outcome: Failure of Conservative Management}

Table 2 shows the failure of conservative management. Nine of $109(8 \%)$ patients had failure of conservative management, $2(2 \%)$ patients required percutaneous abscess drainage and 7 (6\%) patients required emergency surgery within 30 days after presentation. Of the patients who required emergency surgery, a second CT was made in four patients because of clinical deterioration and increasing abdominal pain. These CTs revealed an abscess in two patients and no deterioration of disease in the other two patients. Three of these patients had purulent peritonitis upon surgery, whereas in one patient, no deterioration of disease was seen. Three of the patients who required emergency surgery did not undergo a second $\mathrm{CT}$, but a diagnostic laparoscopy was performed in these patients where a purulent peritonitis was seen.

One patient underwent open sigmoidectomy with diverting ileostomy, three patients underwent laparoscopic sigmoid resection with primary anastomosis, two patients underwent Hartmann procedure and one patient received laparoscopic lavage. Overall median time to treatment failure was 3 (IQR 2-5) days.

\section{Outcome per Initial Treatment Strategy}

Table 2 shows the failure of conservative management per initial treatment strategy, as well as a subgroup analysis of the DIABOLO ${ }^{14}$ patients (who were randomly assigned to either antibiotic or non-antibiotic treatment). Seven of 52 $(13 \%)$ patients in the antibiotic treatment group failed conservative treatment versus 2 of $57(4 \%)$ patients in the nonantibiotic group. There was no statistically significant difference in failure of conservative treatment between patients treated with and without antibiotics $(p=0.083)$. In a subgroup analysis of the 39 DIABOLO $^{14}$ patients, only one patient failed conservative treatment in the antibiotic group versus nil in the non-antibiotic group $(p=0.44)$. 


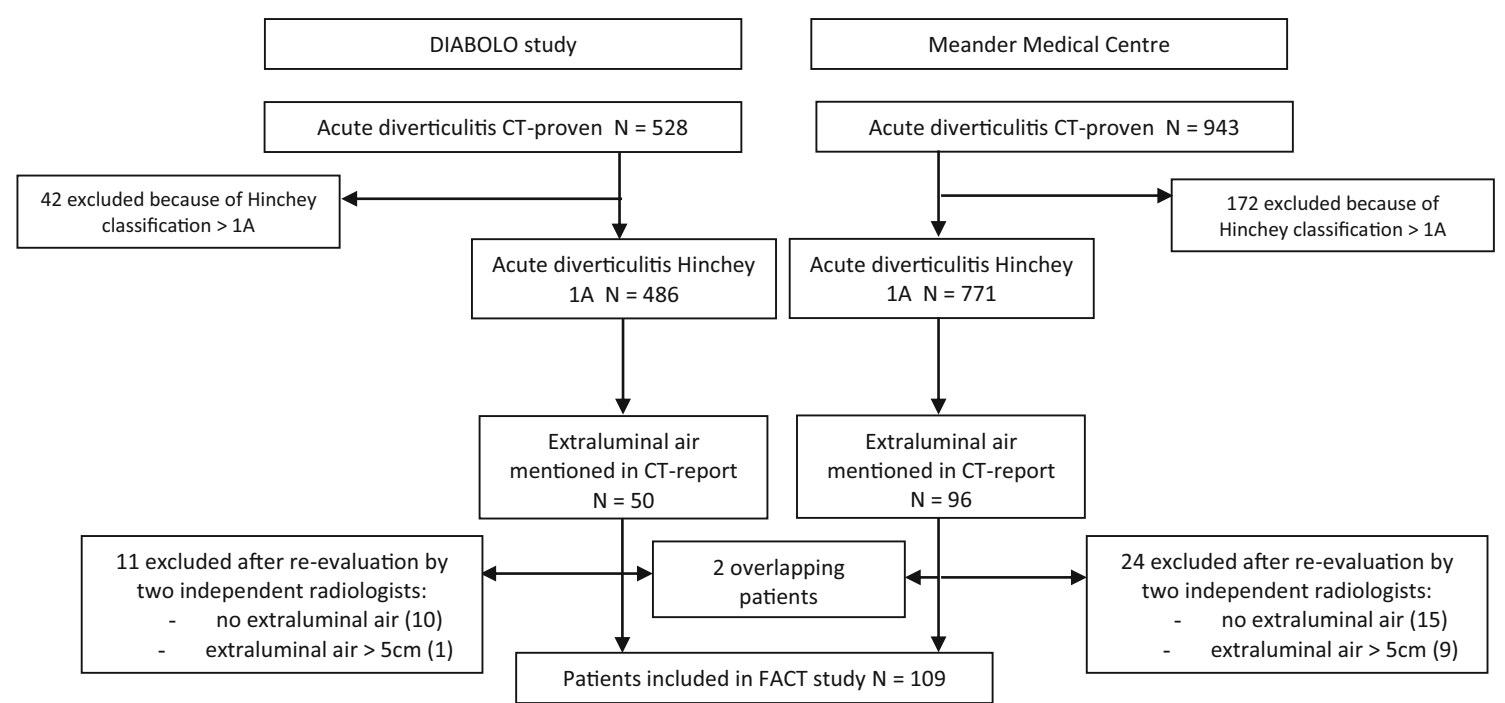

Fig. 1 Flowchart of study patients

\section{Secondary Outcome: Mortality, Complications, $\operatorname{Re}$ (Admittance) and Hospital Stay}

One patient died due to persistent abdominal sepsis following a Hartmann's procedure. Eleven (10\% [11/109]) patients developed complications; colonic obstruction $(n=1)$, perforation $(n=5)$ and abscess $(n=5)$. Forty (37\%) [40/109]) patients were treated as outpatients of which two were eventually admitted to the hospital due to clinical deterioration or development of complications. Fourteen $(35 \%$ [14/40]) of the outpatients were treated with antibiotics. Sixty-nine $(63 \%$ [69/109]) patients were treated as inpatients of which seven (10\% [7/69]) patients were re-admitted to the hospital within 30 days after presentation due to clinical deterioration or development of complications. Thirty-eight (55\% [38/69]) of the inpatients were treated with antibiotics. Two (4\%) patients in the non-antibiotic treatment group were started on antibiotics more than $24 \mathrm{~h}$ after presentation due to clinical deterioration or development of complications. Median length of hospital stay was 3 days (IQR 2-5).

\section{Long-Term Outcomes}

Median follow-up was 11 months (IQR 2-24). Twenty-five of $109(23 \%)$ patients developed recurring diverticulitis, all of whom were treated conservatively. Of the patients with treatment failure $(n=9)$, one $(11 \%)$ patient developed a recurrence. Nineteen of $109(17 \%)$ patients underwent elective sigmoidectomy. Indications for these resections were stenosis $(n=3)$, fistula $(n=3)$ and recurring diverticulitis or persistent complaints $(n=13)$. One patient died due to non-diverticulitis related disease.

\section{Risk Factors for Treatment Failure}

Table 3 shows the univariable and multivariable analyses of factors associated with failure of conservative management (need for percutaneous abscess drainage or emergency surgery). Location of free fluid was not included in the analysis as one radiologist scored these all in Douglas' pouch. The initial treatment strategy (non-antibiotic or antibiotic treatment) was included in the multivariable analysis to correct for a possible treatment effect of antibiotics. In the multivariable analysis, only CRP level (OR 1.01 for each $\mathrm{mg} / \mathrm{L}$ increase; 95\% CI 1.001-1.02) remained statistically significant. Although not statistically significant in the multivariable analysis, leucocyte count and age seemed to be higher in the treatment failure group (mean $18.2 \times 10^{\wedge} 9 / \mathrm{L}$ vs $14.5 \times 10^{\wedge} 9 / \mathrm{L}$ and mean 60 vs 52 years, respectively).

\section{Discussion}

The present study analysed the course of diverticulitis patients presenting with isolated pericolic air on $\mathrm{CT}$. The vast majority (92\%) of patients recovered with conservative treatment. This indicates that diverticulitis patients with isolated pericolic air on CT can safely be treated conservatively.

The clinical relevance of pericolic air on CT in diverticulitis patients presenting without signs of generalised peritonitis or sepsis has been topic of debate. Several studies have recently been published reporting on the non-operative management of perforated diverticulitis. Titos-Garcia et al. ${ }^{14}$ and Salinnen et al. ${ }^{12}$ specifically report non-operative treatment success rates for patients with isolated pericolic air, 90 and 99\% respectively. Both studies only considered emergency surgery as treatment failure. These findings are consistent with our 
Table 1 Patient characteristics

\begin{tabular}{|c|c|c|c|c|}
\hline & All patients $(N=109)$ & No antibiotics $(N=57)$ & Antibiotic treatment $(N=52)^{\mathrm{a}}$ & $P$ value \\
\hline \multicolumn{5}{|l|}{ Patient demographics } \\
\hline Age, mean (SD) & $53(11)$ & $52(11)$ & $55(12)$ & $0.137^{\mathrm{c}}$ \\
\hline Female gender, $N(\%)$ & $36(33 \%)$ & $22(39 \%)$ & $14(27 \%)$ & $0.196^{\mathrm{d}}$ \\
\hline ASA classification & & & & $0.403^{\mathrm{e}}$ \\
\hline ASA I & $65(60 \%)$ & $37(65 \%)$ & $28(54 \%)$ & \\
\hline ASA II & $38(35 \%)$ & $18(32 \%)$ & $20(38 \%)$ & \\
\hline ASA III & $6(5 \%)$ & $2(4 \%)$ & $4(8 \%)$ & \\
\hline BMI kg/m², mean (SD) & $27.6(4.6)$ & $26.6(3.6)$ & $28.9(5.4)$ & $0.026^{\mathrm{c}}$ \\
\hline History of diverticulitis, $N(\%)$ & $10(9 \%)$ & $6(10 \%)$ & $4(9 \%)$ & $0.496^{\mathrm{d}}$ \\
\hline \multicolumn{5}{|l|}{ Clinical status } \\
\hline Temperature ${ }^{\circ} \mathrm{C}$, mean (SD) & $37.6(0.8)$ & $37.5(0.8)$ & $37.7(0.8)$ & $0.118^{\mathrm{c}}$ \\
\hline \multicolumn{5}{|l|}{ Laboratory findings } \\
\hline CRP (mg/L), median (IQR) ${ }^{\mathrm{b}}$ & $124(76-199)$ & $115(73-179)$ & $142(90-218)$ & $0.106^{4}$ \\
\hline Leucocytes $\left(10^{\wedge} 9 / \mathrm{L}\right)$, mean $(\mathrm{SD})^{\mathrm{b}}$ & $14.8(4.1)$ & $14.7(3.6)$ & $14.9(4.6)$ & $0.803^{\mathrm{c}}$ \\
\hline \multicolumn{5}{|l|}{$\mathrm{CT}$ findings } \\
\hline Volume of pericolic air (CC), median IQR & $1.5(1.0-2.5)$ & $1.5(1.0-2.0)$ & $2.0(1.5-3.0)$ & $0.019^{\mathrm{f}}$ \\
\hline Intraperitoneal fluid, $N(\%)$ & $12(11 \%)$ & $9(16 \%)$ & $3(6 \%)$ & $0.096^{\mathrm{d}}$ \\
\hline
\end{tabular}

$S D$ standard deviation, IQR inter quartile range, $A S A$ American Society of Anesthesiologists, $B M I$ body mass index, $C R P C$-reactive protein, $W B C$ white blood cell

${ }^{\mathrm{a}}$ Within $24 \mathrm{~h}$ after presentation

${ }^{\mathrm{b}}$ At presentation

${ }^{\mathrm{c}}$ Independent $T$ test

${ }^{\mathrm{d}} \mathrm{Chi}^{2}$ test

${ }^{\mathrm{e}}$ Fisher's exact test

${ }^{\mathrm{f}}$ Mann-Whitney $U$ test

finding that $92 \%$ of the patients with isolated pericolic air recovered with conservative treatment.

Most studies reporting on the non-operative management of perforated diverticulitis include patients with pericolic and distant free air. The present study only included patients with isolated pericolic air. We selected this patient group because literature suggests that pericolic and distant extraluminal air have a different disease course and demand different treatment strategies. In a patient with distant free air, we can no longer speak of a "covered perforation" as the perforation is no longer contained to the pericolic region. This is why large amounts of free distant air is usually considered a sign of diffuse peritonitis and an indication for operative intervention whereas patients with isolated pericolic air may be treated conservatively. Recent studies report contrastingly about the risk of conservative treatment failure in patient with distant free air. Sallinen et al. ${ }^{12}$, Colas et al. ${ }^{15}$ and Titos-Garcia et al. ${ }^{14}$ report lower success rates of conservative treatment in patients

Table 2 Treatment failure and subgroup analysis of DIABOLO patients

\begin{tabular}{|c|c|c|c|c|}
\hline Present study & All patients $(N=109)$ & No antibiotics $(N=57)$ & Antibiotic treatment $(N=52)^{\mathrm{a}}$ & $P$ value ${ }^{\mathrm{b}}$ \\
\hline Percutaneous drainage $N(\%)$ & $2(2 \%)$ & $0(0 \%)$ & $2(4 \%)$ & 0.23 \\
\hline Emergency surgery $N(\%)$ & $7(6 \%)$ & $2(4 \%)$ & $5(10 \%)$ & 0.26 \\
\hline Total treatment failure $N(\%)$ & $9(8 \%)$ & $2(4 \%)$ & $7(13 \%)$ & 0.08 \\
\hline DIABOLO sub analysis & All patients $(N=39)$ & No antibiotics $(N=22)$ & Antibiotic treatment $(N=17)$ & $P$ value $^{\mathrm{b}}$ \\
\hline Percutaneous drainage $N(\%)$ & $0(0 \%)$ & $0(0 \%)$ & $0(0 \%)$ & - \\
\hline Emergency surgery $N(\%)$ & $1(3 \%)$ & $0(0 \%)$ & $1(6 \%)$ & 0.44 \\
\hline Total treatment failure $N(\%)$ & $1(3 \%)$ & $0(0 \%)$ & $1(6 \%)$ & 0.44 \\
\hline
\end{tabular}

${ }^{\text {a }}$ Received antibiotics within $24 \mathrm{~h}$ after presentation

${ }^{\mathrm{b}}$ Fisher's exact 
Table 3 Factors associated with failure of conservative management

\begin{tabular}{|c|c|c|c|c|c|}
\hline & $\begin{array}{l}\text { Treatment success } \\
(N=100)\end{array}$ & $\begin{array}{l}\text { Treatment failure } \\
(N=9)\end{array}$ & $P$ value & $\begin{array}{l}\text { Unadjusted odds ratio } \\
(95 \% \mathrm{CI})^{\mathrm{a}}\end{array}$ & $\begin{array}{l}\text { Adjusted odds ratio } \\
(95 \% \mathrm{CI})^{\mathrm{b}}\end{array}$ \\
\hline \multicolumn{6}{|l|}{ Patient demographics } \\
\hline Age, mean (SD) & $52(10)$ & $60(13)$ & $0.063^{\mathrm{e}}$ & $1.06(0.996-1.13)$ & $1.03(0.96-1.10)$ \\
\hline Female gender & $34(34 \%)$ & $2(22 \%)$ & $0.715^{\mathrm{g}}$ & $1.80(0.36-9.16)$ & - \\
\hline \multicolumn{6}{|l|}{ ASA classification } \\
\hline & & & $0.837^{\mathrm{g}}$ & & - \\
\hline ASA I & $60(60 \%)$ & $5(56 \%)$ & & \multirow{3}{*}{$\begin{array}{l}\text { Reference } \\
1.41(0.36-5.61) \\
{ }_{c}{ }^{c}\end{array}$} & \\
\hline ASA II & $34(34 \%)$ & $4(44 \%)$ & & & \\
\hline ASA III & $6(6 \%)$ & $0(0 \%)$ & & & \\
\hline BMI kg/m², mean (SD) & $27.7(4.6)$ & $25.6(3.9)$ & $0.369^{\mathrm{e}}$ & $0.86(0.63-1.18)$ & - \\
\hline History of diverticulitis & $9(10 \%)$ & $1(11 \%)$ & $1.000^{\mathrm{g}}$ & $0.87(0.10-7.96)$ & - \\
\hline \multicolumn{6}{|l|}{ Clinical status } \\
\hline Temperature ${ }^{\circ} \mathrm{C}$, mean (SD) & $37.6(0.8)$ & $37.5(0.9)$ & $0.723^{\mathrm{e}}$ & $0.85(0.35-2.07)$ & - \\
\hline \multicolumn{6}{|l|}{ Laboratory findings } \\
\hline CRP (mg/L), median (IQR) & $124(75-192)$ & $218(97-364)$ & $0.029^{4}$ & $1.01(1.004-1.02)$ & $1.01(1.001-1.02)$ \\
\hline Leucocytes $\left(10^{\wedge} 9 / \mathrm{L}\right)$, mean $(\mathrm{SD})$ & $14.5(4.0)$ & $18.2(3.6)$ & $0.008^{\mathrm{e}}$ & $1.24(1.05-1.48)$ & $1.20(0.99-1.45)$ \\
\hline \multicolumn{6}{|l|}{ CT findings } \\
\hline Volume of pericolic air (CC), median IQR & $1.5(1.0-2.5)$ & $2.0(1.0-4.0)$ & $0.806^{\mathrm{h}}$ & $1.02(0.98-1.06)$ & - \\
\hline Intraperitoneal fluid & $11(11 \%)$ & $1(11 \%)$ & $1.000^{\mathrm{g}}$ & $0.94(0.11-8.28)$ & - \\
\hline \multicolumn{6}{|l|}{ Initial treatment } \\
\hline Antibiotic treatment $^{\mathrm{d}}$ & $45(45 \%)$ & $7(78 \%)$ & $0.083^{\mathrm{f}}$ & $4.28(0.85-21.62)$ & $2.48(0.43-14.40)$ \\
\hline
\end{tabular}

$S D$ standard deviation, $I Q R$ inter quartile range, $N S$ not selected, $C R P$ C-reactive protein, $A S A$ American Society of Anesthesiologists, $B M I$ body mass index, $C I$ confidence interval

${ }^{\text {a }}$ Odds ratio in univariable analysis

${ }^{\mathrm{b}}$ Odds ratio in multivariable analysis

${ }^{\mathrm{c}}$ Odds ratio could not be calculated because zero events occurred in this group

${ }^{\mathrm{d}}$ Within $24 \mathrm{~h}$ after presentation

${ }^{\mathrm{e}}$ Independent $T$ test

${ }^{\mathrm{f}} \mathrm{Chi}^{2}$ test

${ }^{\mathrm{g}}$ Fisher's exact test

${ }^{\mathrm{h}}$ Mann-Whitney $U$ test

with distant free air; $62 \%, 59 \%$ and $62 \%$, respectively. Contrastingly, Dharmarajan et al. ${ }^{13}$ and Costi et al. ${ }^{11}$ report no difference in outcome between pericolic and distant free air. However, the number of patients presenting with distant free air was relatively small in these studies, hampering proper comparison. As patients with free distant air do show a tendency towards a more complicated course, including these patients would have led to a heterogeneous study population. We therefore chose to only include patients with isolated pericolic air to assess the outcome of (non-antibiotic) conservative treatment.

The question remains which therapeutic approach we should adopt in diverticulitis patients with pericolic air on CT. A recent systematic review, including the studies mentioned above, concludes that conservative treatment in patients with pericolic air is justifiable but should include antibiotic treatment, as all patients included in this study received intravenous antibiotics as part of their non-operative management. ${ }^{21}$ Since we found a conservative treatment success rate of $92 \%$ in the present study, we agree that conservative treatment is appropriate in this patient group. The rationale for antibiotic treatment is however not well-founded and might be questioned. Fifty-seven (52\%) of our patients were treated without antibiotics and of these, 55 (96\%) patients were treated successfully. The baseline characteristics of the antibiotic and non-antibiotic group were mostly comparable. C-reactive protein (CRP) seemed to be slightly higher in the antibiotic group (median 142 versus $115 \mathrm{mg} / \mathrm{L}$ ), and the volume of pericolic air was significantly higher in the antibiotic group (median 2.0 versus $1.5 \mathrm{cc}$ ) compared to the nonantibiotic group. The clinical relevance of this marginal difference is however debatable, especially since accurate measurement of amount of free air on CT is difficult and subjective. We found no statistical significant difference in failure of 
conservative treatment between patients treated with and without antibiotics $(p=0.083)$. This could indicate that antibiotic treatment might not be mandatory in patients with pericolic air. However, $64 \%$ of the study population came from a retrospective database and in these patients, antibiotic treatment was started at the discretion of the attending physician. Therefore, there is a high risk of confounding by indication. It is possible that patients who presented with more severe illness (who might be at higher risk of conservative treatment failure) were more likely to receive antibiotic treatment and therefore, these findings should be interpreted very carefully. In a subgroup analysis of the DIABOLO ${ }^{14}$ patients (who were randomly assigned to either watchful waiting or antibiotic treatment), there was also no difference in outcome found between patients treated with and without antibiotics, strengthening our conclusion that antibiotics may not be mandatory in patients with pericolic air. However, further research aimed at the non-antibiotic treatment of diverticulitis patients with isolated pericolic air should be performed before a conservative treatment strategy without antibiotics can safely be assumed. Sixty-three [69/100] percent of the patients were directly admitted to the hospital, whereas $37 \%$ [40/109] were treated as outpatients. The decision to admit a patient to the hospital was made by the attending physician based on individual patient characteristics. We chose to include both inpatients and outpatients in our analysis as previous literature has provided strong evidence that in-hospital treatment of patients with uncomplicated diverticulitis does not have a beneficial effect compared to outpatient treatment. ${ }^{22-27}$

A major strength of this study is its multicenter design and the fact that one third of the study population came from a prospective, randomised study. Contrastingly, the other twothird of the study population came from a retrospective database which comes with inherent limitations. Since we were dependent on the information that was recorded in the patient files of the retrospective cohort, we could not analyse all potential risk factors for treatment failure such as body mass index or immunosuppressive medication as we had too little data on these factors. The fact that two independent radiologist re-analysed all CTs enhances the validity of our results. However, a limitation is that we did not re-analyse all CT scans in which free air was not mentioned in the CT-report, to confirm the absence of free air. It could therefore be that we missed a few patients with free air. Moreover, in the DIABOLO study, diverticulitis-positive findings led to CT within $24 \mathrm{~h}$ and it could be that these patients had resolution of their free air in that meantime.

The present study is limited by the small number of patients with treatment failure. In the multivariable analysis, only a higher CRP level remained as a significant predictor of treatment failure. Although not statistically significant, a higher leucocyte count and higher age seemed to be associated with treatment failure. Because of the small number of treatment failures, statistical power might have been insufficient to identify risk factors for treatment failure. The primary aim of this study was however to assess the feasibility of (non-antibiotic) conservative management in patients with pericolic air, and the small number reflects the low probability of treatment failure in patients with isolated pericolic air.

\section{Conclusion}

Conservative management in patients with acute diverticulitis with isolated pericolic air is a suitable treatment strategy. It however remains uncertain whether antibiotic treatment is necessary in patients with isolated pericolic air, due to the low event rate. A higher CRP level was significantly associated with treatment failure, and a higher leucocyte count and higher age showed a non-significant trend towards an association with treatment failure. Patients with isolated pericolic air who present with these risk factors may not be suitable for a conservative treatment strategy and need close observation and/or treatment with antibiotics.

Author Contribution HE Bolkenstein and S van Dijk were involved in the study design, data acquisition, data analysis, interpretation of the data and writing of the report. CM Hoeks and BGF Heggelman were involved in the data acquisition, interpretation of the data and writing of the report. ECJ Consten, IAMJ Broeders, WA Boermeester and WA Draaisma were involved in the study design, interpretation of the data and writing of the report. All the authors gave final approval of the version to be published and agree to be accountable for all aspects of the work.

\section{Compliance with Ethical Standards}

The study was approved by the local Institutional Review Board of the Meander Medical Centre.

Conflict of Interest The authors declare that they have no conflict of interest.

Open Access This article is distributed under the terms of the Creative Commons Attribution 4.0 International License (http:// creativecommons.org/licenses/by/4.0/), which permits unrestricted use, distribution, and reproduction in any medium, provided you give appropriate credit to the original author(s) and the source, provide a link to the Creative Commons license, and indicate if changes were made.

Publisher's Note Springer Nature remains neutral with regard to jurisdictional claims in published maps and institutional affiliations.

\section{References}

1. Shahedi K, Fuller G, Bolus R. Long-term risk of acute diverticulitis among patients with incidental diverticulosis found during colonoscopy. Clin Gasteroenterol Hepatol 2013. 11(12): 1609-13 
2. Loffield RJ. Long-term follow-up and development of diverticulitis in patients diagnosed with diverticulosis of the colon. Int J Color Dis 2016. 31(1):15-7

3. Tursi A, Papa A, Danese S. Review article: the pathogenesis and medical management of diverticulosis and diverticular disease of the colon. Aliment Pharmacol Ther 2015;42(6):664-84

4. Søreide K, Boermeester MA, Humes DJ, Velmahos GC. Acute colonic diverticulitis: modern understanding of pathomechanisms, risk factors, disease burden and severity. Scand J Gastroenterol 2016;51(12):1416-1422.

5. Klarenbeek BR, de Korte N, van der Peet DL, Cuesta MA. Review of current classifications for diverticular disease and a translation into clinical practice. Int J Color Dis 2012;27:207-2014

6. Mora Lopez L, Serra Pla S, Serra-Aracil X, Ballesteros E, Navarro S. Application of a modified Neff classification to patients with uncomplicated diverticulitis. Color Dis 2013;15:1442-7

7. Sallinen VJ, Leppäniemi AK, Mentula PJ. Staging of acute diverticulitis based on clinical, radiologic, and physiologic parameters. J Trauma Acute Care Surg 2015;78:543-51

8. Sartelli M, Moore FA, Ansaloni L, Di Saverio S, Coccolini F, Griffiths EA, Coimbra R, Agresta F, Sakakushev B, Ordoñez CA, Abu-Zidan FM, Karamarkovic A, Augustin G, Costa Navarro D, Ulrych J, Demetrashvili Z, Melo RB, Marwah S, Zachariah SK, Wani I, Shelat VG, Kim JI, McFarlane M, Pintar T, Rems M, Bala M, Ben-Ishay O, Gomes CA, Faro MP, Pereira GA Jr, Catani M, Baiocchi G, Bini R, Anania G, Negoi I, Kecbaja Z, Omari AH, Cui Y, Kenig J, Sato N, Vereczkei A, Skrovina M, Das K, Bellanova G, Di Carlo I, Segovia Lohse HA, Kong V, Kok KY, Massalou D, Smirnov D, Gachabayov M, Gkiokas G, Marinis A, Spyropoulos C, Nikolopoulos I, Bouliaris K, Tepp J, Lohsiriwat V, Çolak E, Isik A, Rios-Cruz D, Soto R, Abbas A, Tranà C, Caproli E, Soldatenkova D, Corcione F, Piazza D, Catena F. A proposal for a CT driven classification of left colon acute diverticulitis. World J Emerg Surg 2015;10:3

9. Ritz JP, Lehmann KS, Loddenkemper C, Frericks B, Buhr HJ, Holmer C (2010) Preoperative CT staging in sigmoid diverticulitis - does it correlate with intraoperative and histological findings? Langenbeck's Arch Surg 395:1009-1015

10. Vennix S, Morton DG, Hahnloser D, Lange JF, Bemelman WA; Research Committee of the European Society of Coloproctocology. Systematic review of evidence and consensus on diverticulitis: an analysis of national and international guidelines. Color Dis 2014;16(11):866-78

11. Costi R, Cauchy F, Le Bian A, Honart JF, Creuze N, Smadja C. Challenging a classic myth: pneumoperitoneum associated with acute diverticulitis is not an indication for open or laparoscopic emergency surgery in hemodynamically stable patients. A 10-year experience with a nonoperative treatment Surg Endosc 2012;26(7): 2061-71

12. Sallinen VJ, Mentula PJ, Leppaniëmi AK. Nonoperative management in perforated diverticulitis with extraluminal air is safe and effective in selected patients. Dis Colon Rectum 2014; 57: 875-881

13. Dharmarajan S, Hunt SR, Birnbaum EH, Fleshman JW, Mutch MG. The efficacy of nonoperative management of acute complicated diverticulitis. Dis Colon Rectum 2011; 54: 663-671
14. Titos-Garcia A, Aranda-Narvaez JM, Romacho-Lopez L, Gonzalez-Sanchez AJ, Cabrera-Serna I, Santoyo-Santoyo J. Nonoperative management of acute perforated diverticulitis with extraluminal air: results and risk factors for failure. Int J Color Dis (2017) 32:1503-1507

15. Colas PA, Duchalais E, Duplay Q, Serra-Maudet V, Kanane S, Ridereau-Zins C, Lermite E, Aubé C, Hamy A, Venara A. Failure of conservative treatment of acute diverticulitis with extradigestive air. World J Surg (2017) 41:1890-1895

16. Daniels L, Ünlü Ç, de Korte N, van Dieren S, Stockmann HB, Vrouenraets BC, Consten ECJ, van der Hoeven JA, Eijsbouts QA, Faneyte IF, Bemelman WA, Dijkgraaf MG, Boermeester MA, Dutch Diverticular Disease (3D) Collaborative Study Group. Randomized clinical trial of observational versus antibiotic treatment for a first episode of CT-proven uncomplicated acute diverticulitis. Br J Surg 2017;104(1):52-61

17. Hinchey EJ, Schaal PG, Richards GK. Treatment of perforated diverticular disease of the colon. Adv Surg 1978;12:85-109

18. Wasvary H, Turfah F, Kadro O, Beauregard W. Same hospitalization resection for acute diverticulitis. Am Surg 1999;65:632-635

19. Kaiser AM, Jiang JK, Lake JP, Ault G, Artinyan A, Gonzalez-Ruiz C, Essani R, Beart RW Jr. The management of complicated diverticulitis and the role of computed tomography. Am J Gastroenterol 2005;100:910-917

20. American College of Chest Physicians/Society of Critical Care Medicine. Consensus Conference: definitions for sepsis and organ failure and guidelines for the use of innovative therapies in sepsis. Crit Care Med 1992; 20: 864-874

21. van Dijk ST, Doelare SAN, van Geloven AAW, Boermeester MA. A Systematic Review of Pericolic Extraluminal Air in Left-Sided Acute Colonic Diverticulitis. Surg Infect 2018;19(4):362-368

22. Isacson D, Thorisson A, Andreasson K, Nikberg M, Smedh K, Chabok A. Outpatient, non-antibiotic management in acute uncomplicated diverticulitis: a prospective study. Int J Color Dis 2015. 30: 1229-1234

23. Joliat G, Emery J, Demartines N, Hübner M, Yersin B, Hahnloser D. Antibiotic treatment for uncomplicated and mild complicated diverticulitis: outpatient treatment for everyone. Int J Color Dis 2017. 32(9):1313-1319

24. Etzioni DA, Chiu VY, Cannom RR, Burchette RJ, Haigh PI, Abbas MA. Outpatient treatment of acute diverticulitis; rates and predictors of treatment failure. Dis Colon Rectum 2010;53(6):861-65

25. Jackson JD, Hammond T. Systematic review; outpatient management of acute uncomplicated diverticulitis. Int J Color Dis 2014; 29(7):775-81

26. Biondo S, Golda T, Kreisler E, Espin E, Vallribera F, Oteiza F, Codina-Cazador A, Pujadas M, Flor B. Outpatient versus hospitalization management for uncomplicated diverticulitis. A prospective, multicenter randomized clinical trial (DIVER trial). Ann Surg 2014;259;38-44

27. Unlu C, Gunadi PM, Gerhards MF, Boermeester MA, Vrouenraets BC. Outpatient treatment for acute uncomplicated diverticulitis. Eur J Gastroenterol Hepatol 2013. 25(9):1038-1043 